\title{
Practical and Highly Enantioselective Synthesis of $\beta$-Alkynyl- $\beta$ - Amino Esters Through Ag-Catalyzed Asymmetric Mannich Reactions of Silylketene Acetals and Alkynyl Imines
}

\author{
Nathan S. Josephsohn, Emma L. Carswell, Marc L. Snapper, and Amir H. Hoveyda \\ Department of Chemistry, Merkert Chemistry Center, Boston College Chestnut Hill, Massachusetts \\ 02467
}

\begin{abstract}

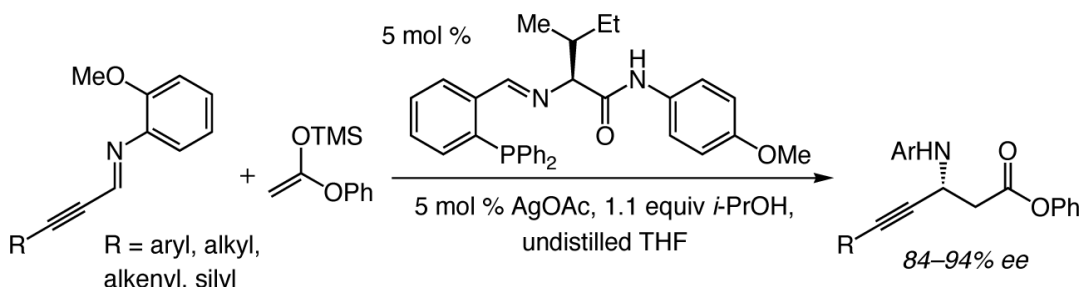

A readily available iso-leucine-based phosphine ligand is used to promote Ag-catalyzed Mannich reactions between silylketene acetals and various alkynyl imines. Reactions can be effected in the presence of $5 \mathrm{~mol} \%$ catalyst, without the need for rigorous exclusion of air, and with commercially available solvents (without purification) to afford the desired $\beta$-alkynyl- $\beta$-amino esters in $84-94 \%$ ee and $61-91 \%$ isolated yield.
\end{abstract}

$\beta$-Amino acids and derivatives constitute an important class of organic molecules critical to the preparation of a variety of biologically significant molecules. ${ }^{1}$ Accordingly, in recent years a number of efforts have focused on the development of efficient and stereoselective methods that allow access to such compounds. ${ }^{1}$ In terms of related catalytic asymmetric methods, enantioselective hydrogenations of $\beta$-amino acrylates ${ }^{2}$ and conjugate additions of $\mathrm{N}$-based nucleophiles to unsaturated carbonyls ${ }^{3}$ have been introduced. Moreover, several investigations have been concerned with catalytic asymmetric additions of different enolate equivalents to imines (Mannich reactions). ${ }^{4}$

Although significant advances in the development of methods for the synthesis of $\beta$-amino esters have occurred, a number of challenges in connection with substrate generality persist. Regarding catalytic asymmetric Mannich reactions, one critical issue arises from the fact that nearly all the investigations to date have focused on transformations that deliver $\beta$-amino esters that bear a $\beta$-ester 5,6 or a $\beta$-aryl group 4 (reactions of imines derived from aromatic aldehydes). There are only a few cases where $\alpha, \beta$-unsaturated imines are used, and methods that yield $\beta$ alkyl amino esters are relatively scarce, particularly those that deliver high enantioselectivities (>90\% ee). ${ }^{6,7}$ Finally, to the best of our knowledge, none of the catalytic asymmetric methods disclosed so far deliver $\beta$-alkynyl- $\beta$-amino esters. ${ }^{8}$

amir.hoveyda@bc.edu.

Supporting Information Available. Experimental and analytical data for substrates and products. This material is available free of charge via the Internet at http://pubs.acs.org. 
As summarized in Scheme 1, we recently disclosed an efficient Ag-catalyzed method for enantioselective addition of silyl enol ethers to a variety of imines to afford the desired $\beta$-amino ketones in high enantioselectivity (typically $>90 \%$ ee). ${ }^{9}$ One notable attribute of the above protocol is that it is not limited to reactions of aryl imines; alkyl, alkenyl and alkynyl imines can be used as well.

Based on such recent advances, and considering the above mentioned methodological deficiencies, we set out to establish whether the catalytic system depicted in Scheme 1 can be used to effect catalytic asymmetric Mannich reactions between non-aryl imines and silyl ketene acetals.

Herein, we report a highly efficient Ag-catalyzed enantioselective method for the addition of silyl ketene acetals to a variety of alkynyl imines (eq 1). The catalytic asymmetric protocol delivers the desired $\beta$-alkynyl- $\beta$-amino esters in up to $94 \%$ ee; optically enriched amino esters are readily converted to a number of synthetically useful derivatives (e.g., $\beta$-alkyl- $\beta$-amino esters). The Ag-catalyzed transformation requires a chiral phosphine ligand (1) that can be easily prepared from commercially available materials, including an inexpensive amino acid (iso-Leu). Moreover, the enantioselective processes can be carried out in air without the need for purified solvent.

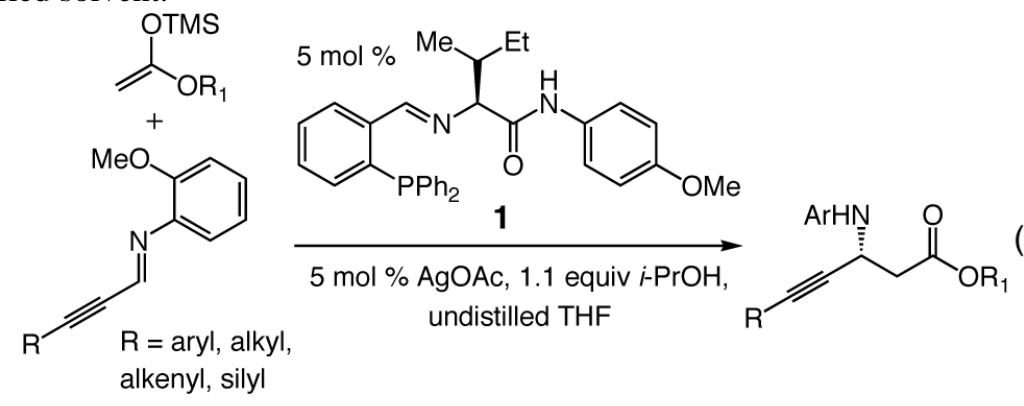

As the data summarized in Table 1 indicate, Ag- catalyzed addition of silyl ketene acetal $\mathbf{3}$ to a wide range of alkynyl imines (2a-h) proceeds smoothly at $-60{ }^{\circ} \mathrm{C}$ to afford $\beta$-amino esters 4a-h in 61-91\% isolated yield and $84-94 \%$ ee (>98\% conv in all cases). It is noteworthy that the Ag-catalyzed protocol is equally efficient and enantioselective with alkynyl imines that bear silyl (entry 1), aryl (entries 2-4), alkyl (entries 5-6,8) and alkenyl (entry 7) substituents.

Our investigation focused on transformations with phenyl ester $\mathbf{3}$ for several reasons: (a) Initial studies indicated that other ester derivatives (e.g., $t$-butyl esters) undergo efficient addition but in lower enantioselectivity (see Scheme 2 for an example). (b) Preparation of silylketene acetal $\mathbf{3}$ is typically more convenient and efficient than ketene acetals derived from alkyl esters (vs phenyl ester). (c) Phenyl esters can be more readily converted to a variety of other esters. (d) Preliminary screening indicated that catalytic asymmetric additions with $t$-butyl(dimethyl)silyl ketene acetals affords significantly lower enantioselectivities $(<50 \%$ ee).

Next, we examined several key functionalizations that may be carried out with optically enriched $\beta$-alkynyl amino esters. Thus, as illustrated by the example in eq (2), Pd-catalyzed hydrogenation of $\mathbf{4 d}$ (obtained in $92 \%$ ee) leads to the formation of $\beta$-amino ester $\mathbf{5}$ in $84 \%$ isolated yield after silica gel chromatography. It is important to note that, under the conditions outlined in Table 1, imines derived from aliphatic aldehydes do not provide the desired product in the presence of silyl ketene acetal 3 ( $<2 \%$ conv by $400 \mathrm{MHz}{ }^{1} \mathrm{H}$ NMR analysis). 


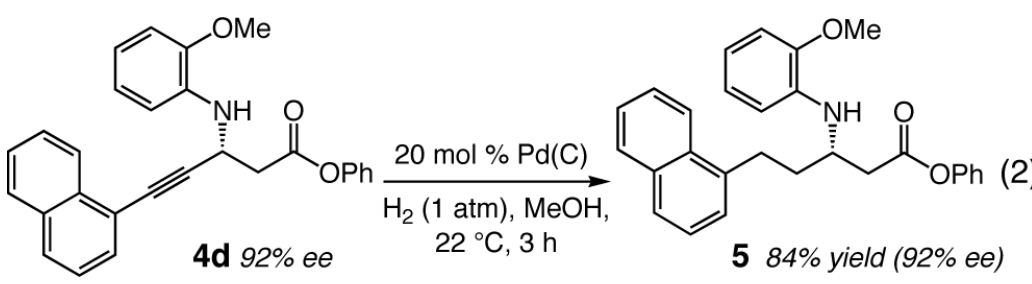

As demonstrated by preparation of Boc-protected $\beta$-amino ester $\mathbf{6}$ from $\mathbf{4 b}$ ( $68 \%$ isolated yield), shown in Scheme 2, removal of the N-activating group is effected oxidatively through a procedure developed in these laboratories, ${ }^{10}$ concomitant with installment of an amide unit. In a similar fashion, as also depicted in Scheme 2, oxidative removal of the anisidyl unit of $\mathbf{4 b}(94 \%$ ee) in the presence of activated optically pure amino acid $\mathbf{7}$ leads to the formation of 8 in $73 \%$ yield and $>98 \%$ ee after silica gel chromatography.

Synthesis of $t$-butyl ester 10 , which proceeds in $61 \%$ isolated yield to afford the desired product in $>98 \%$ ee is noteworthy for two reasons. (a) It provides an illustration of the lower enantioselectivity of Ag-catalyzed reactions involving silyl ketene acetals of alkyl esters (72\% ee vs 94\% ee obtained with ketene acetal 3). (b) The oxidative conditions used for the removal of the anisidyl unit are compatible with an acid-sensitive group such as a $t$-butyl ester. Optically enriched $\beta$-amino esters that contain a $\beta$-alkyne group can serve as versatile building blocks in the synthesis of biologically active molecules. ${ }^{11}$

In summary, we have developed an efficient Ag-catalyzed method for enantioselective synthesis of $\beta$-alkynyl- $\beta$-amino acids, a class of compounds that cannot be accessed by other catalytic enantioselective Mannich protocols. The optically enriched (84-94\% ee) products obtained can be functionalized in a number of ways to afford a range of useful $\beta$-amino esters. Hydrogenation of the alkyne group delivers difficult-to-access $\beta$-alkyl- $\beta$-amino esters.

Removal of the $\mathrm{N}$-activating group can be effected en route to optically enriched unprotected $\beta$-amino esters or, alternatively, after in situ coupling with activated esters, to a variety of amides.

Future studies will focus on the development of other catalytic asymmetric Mannich reactions and related applications to the synthesis of biologically significant molecules.

\section{Supplementary Material}

Refer to Web version on PubMed Central for supplementary material.

\section{Acknowledgments}

This paper is dedicated to Professor Richard R. Schrock on the occasion of his sixtieth birthday. Financial support was generously provided by the NIH (GM-57212). N. S. J. is grateful to Schering-Plough Research Institute for a graduate fellowship.

\section{References}

1. For related reviews, see: aJuaristiEEnantioselective Synthesis of $\beta$-Amino Acids1997Wiley-VCHNew York b Ma J-A. Angew. Chem., Int. Ed 2003;42:4290-

4299.cKleinmannFFTrostBMFlemingIComprehensive Organic Synthesis19912Pergamon PressNew YorkChapter 4.1 d Cardillo G, Tomasini C. Chem. Soc. Rev 1996:117-128. e Juaristi E, Lopez-Ruiz H. Curr. Med. Chem 1999;6:983-1004. [PubMed: 10519909] e Beddow JE, Davies SG, Smith AD, Russell AJ. Chem. Commun 2004:2778-2779.and references cited therein

2. For recent examples, see: aTangWZhangXOrg. Lett20024,41594161 [PubMed: 12423111] b Zhou YG, Tang W, Wang W-B, Li W, Zhang X. J. Am. Chem. Soc 2002;124:4952-4953. [PubMed: 
11982347] c Tang W, Wang W, Chi Y, Zhang X. Angew. Chem., Int. Ed 2003;42:3509-3511. c Hsiao Y, Rivera NR, Rosner T, Krska SW, Njolito E, Wang F, Sun Y, Armstrong JD, Grabowski EJJ, Tillyer RD, Spindler F, Malan C. J. Am. Chem. Soc 2004;126:9918-9919. [PubMed: 15303855]

3. a Myers JK, Jacobsen EN. J. Am. Chem. Soc 1999;121:8959-8960. b Horstmann TE, Guerin DJ, Miller SJ. Angew. Chem., Int. Ed 2000;39:3635-3638. c Sibi MP, Asano Y. J. Am. Chem. Soc 2001;123:9708-9709. [PubMed: 11572706] d Guerin DJ, Miller SJ. J. Am. Chem. Soc 2002;124:2134-2136. [PubMed: 11878965] e Sibi MP, Prabagaran N, Ghorpade SG, Jasperse CP. J. Am. Chem. Soc 2003;125:11796-11797. [PubMed: 14505383]

4. For examples of catalytic asymmetric Mannich reactions with ester-derived nucleophiles and nonactivated imines, see: a Isgitani H, Ueno M, Kobayashi S. J. Am. Chem. Soc 1997;119:7153-7154. b Xue S, Yu S, Deng Y, Wulff WD. Angew. Chem., Int. Ed 2001;40:2271-2274. c Wenzel AG, Jacobsen EN. J. Am. Chem. Soc 2002;124:12964-12965. [PubMed: 12405820] d Bernardi L, Gothelf AS, Hazell RG, Jorgensen KA. J. Org. Chem 2003;68:2583-2591. [PubMed: 12662026] e Akiyama T, Itoh J, Yokota K, Fuchibe K. Angew. Chem., Int. Ed 2004;43:1566-1568. f Cozzi PG, Rivalta E. Angew. Chem., Int. Ed 2005;44ASAP

5. For representative examples of metal-catalyzed asymmetric Mannich reactions involving glyoxylatederived imines, see: a Ferraris D, Young B, Dudding T, Lectka T. J. Am. Chem. Soc 1998;120:45484549. b Fujii A, Hagiwara E, Sodeoka M. J. Am. Chem. Soc 1999;121:5450-5458. c Trost BM, Terrell LR. J. Am. Chem. Soc 2003;125:338-339. [PubMed: 12517138] d Kobayashi S, Matsubara R, Nakamura Y, Kitagawa H, Sugiura M. J. Am. Chem. Soc 2003;125:2507-2515. [PubMed: 12603138] e Uraguchi D, Terada M. J. Am. Chem. Soc 2004;126:5356-5357. [PubMed: 15113196] f Ooi T, Kameda M, Fujii J, Maruoka K. Org. Lett 2004;6:2397-2399. [PubMed: 15228288]

6. For examples of Mannich reactions promoted by chiral organic catalysts, see: a List B, Pojarliev P, Biller WT, Martin HJ. J. Am. Chem. Soc 2002;124:827-833. [PubMed: 11817958] b Notz W, Tanaka F, Barba CF. Acc. Chem. Res 2004;37:580-591. [PubMed: 15311957] c Cordova A. Chem. Eur. J 2004;10:1987-1997.

7. a Kobayashi S, Kobayashi J, Ishiani H, Ueno M. Chem. Eur. J 2002;8:4185-4190. b Matsunaga S, Yoshida T, Morimoto H, Kumagai N, Shibasaki M. J. Am. Chem. Soc 2004;126:8777-8785. [PubMed: 15250731]

8. For an example of a non-catalytic enantioselective synthesis of a $\beta$-alkynyl- $\beta$-amino ester, see: Saito S, Hatanaka K, Yamamoto H. Org. Lett 2000;2:1891-1894. [PubMed: 10891184]

9. For other Ag-catalyzed asymmetric reactions promoted in the presence of phosphine 1, see: a Josephsohn NS, Snapper ML, Hoveyda AH. J. Am. Chem. Soc 2003;125:4018-4019. [PubMed: 12670201] b Josephsohn NS, Snapper ML, Hoveyda AH. J. Am. Chem. Soc 2004;126:3734-3735. [PubMed: 15038725]

10. a Porter JR, Traverse JF, Hoveyda AH, Snapper ML. J. Am. Chem. Soc 2001;123:10409-10410. [PubMed: 11604001] b Akullian LC, Snapper ML, Hoveyda AH. Angew. Chem., Int. Ed 2003;42:4244-4247. c Traverse JF, Hoveyda AH, Snapper ML. Org. Lett 2003;5:3273-3275. [PubMed: 12943405]

11. For example, see: a Zablocki JA, Rico JG, Garland RB, Rogers TE, Williams K, Schretzman LA, Rao SA, Bovy PR, Tjoeng FS, Lindmark RJ, Toth MV, Zupec ME, McMakins DE, Adams SP, Miyano M, Markos CS, Milton MN, Paulson S, Herin M, Jacmin P, Nicholson NS, Panzer-Knodle SG, Haas NF, Page JD, Szalony JA, Taite BB, Salyers AK, King LW, Campion JG, Feigen L. J. Med. Chem 1995;38:2378-2394. [PubMed: 7608903] b Cossy J, Schmitt A, Cinquin C, Buisson D, Belotti D. J. Med. Chem. Lett 1997;7:1699-1700. 


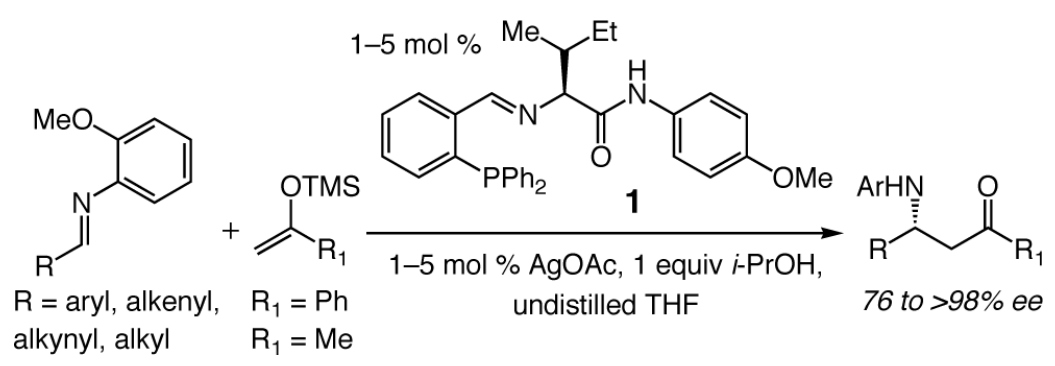

Scheme 1.

Ag-catalyzed enantioselective synthesis of $\beta$-amino ketones 

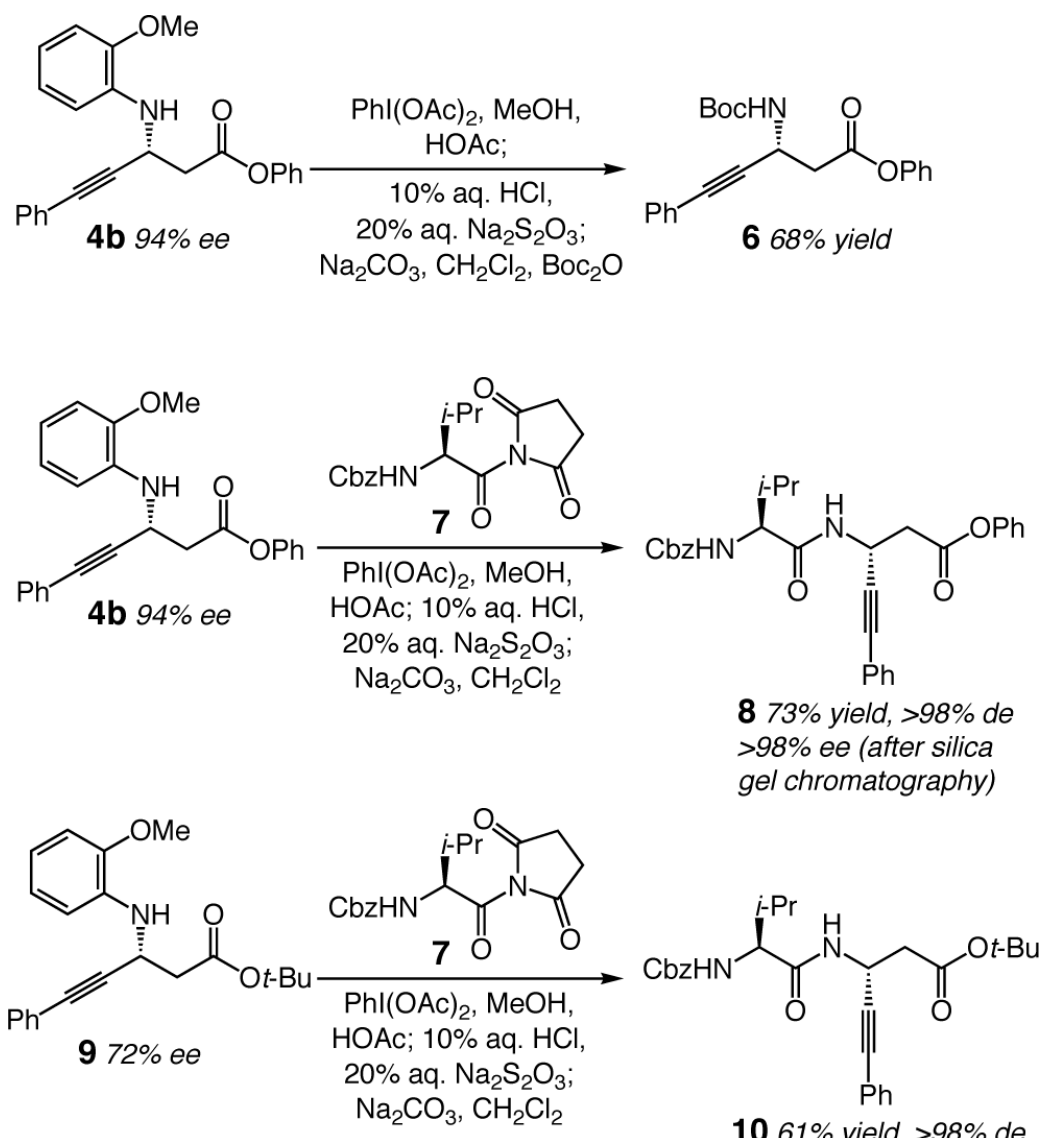

$1061 \%$ yield, $>98 \%$ de $>98 \%$ ee (after silica gel chromatography)

Scheme 2.

One-pot removal of $\mathrm{N}$-activating group and subsequent functionalization 
Table 1

Ag-catalyzed enantioselective Mannich reaction of silylketene acetal $\mathbf{3}$ to alkynyl imines $\mathbf{2} \mathbf{a}-\mathbf{h}$

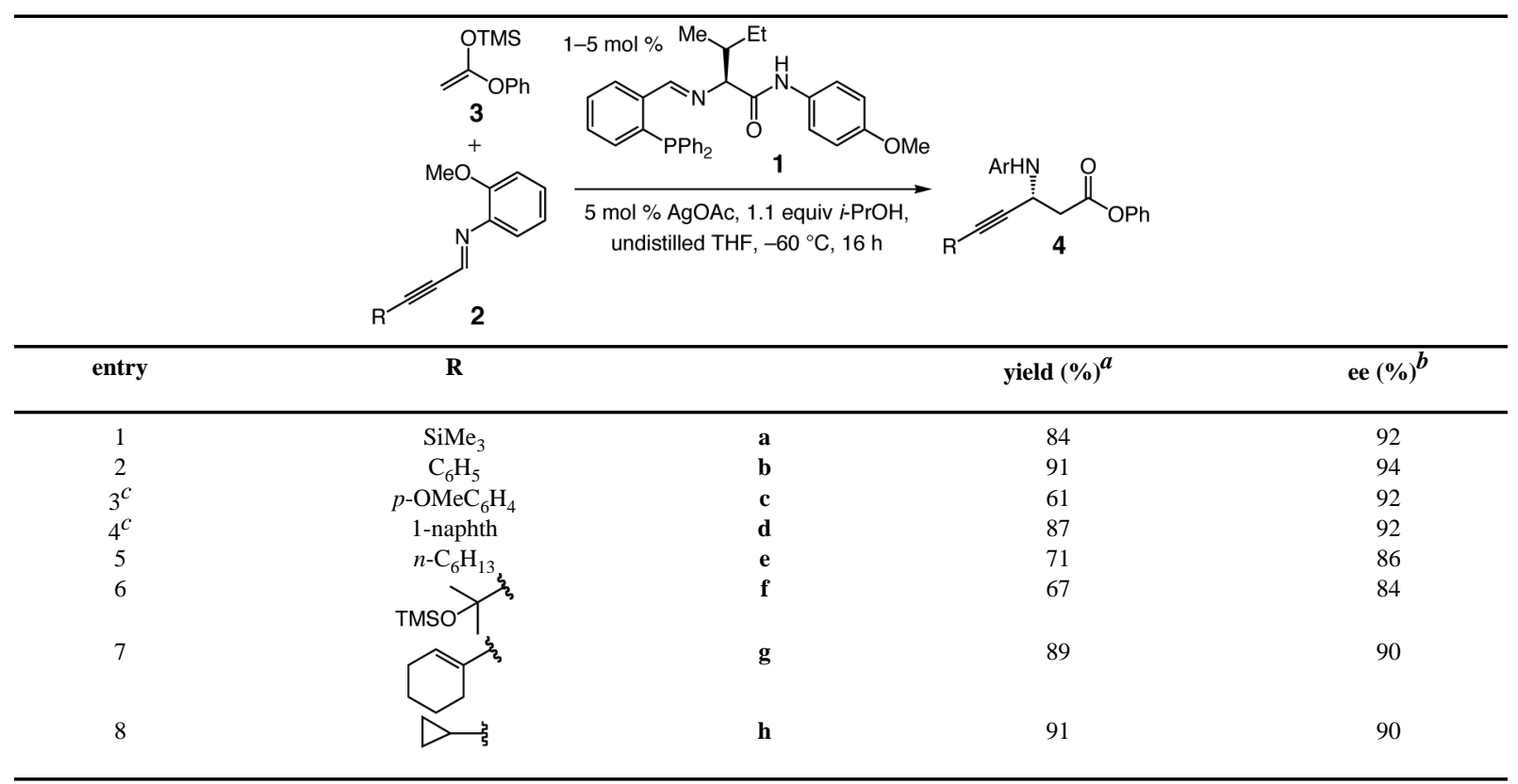

${ }^{a}$ Isolated yields after silica gel chromatography; all reactions proceeded to $>98 \%$ conv., based on $400 \mathrm{MHz}{ }^{1} \mathrm{H}$ NMR analysis

${ }^{b}$ Determined by chiral HPLC analysis; see the Supporting Information for details.

${ }^{c}$ Reaction times are $36 \mathrm{~h}$. 